\title{
Genome wide analysis and clinical correlation of chromosomal and transcriptional mutations in cancers of the biliary tract
}

\author{
George Miller ${ }^{1}$, Nicholas D Socci ${ }^{2}$, Deepti Dhall ${ }^{3}$, Michael D'Angelica4, \\ Ronald P DeMatteo ${ }^{4}$, Peter J Allen ${ }^{4}$, Bhuvanesh Singh ${ }^{4}$, Yuman Fong ${ }^{4}$, \\ Leslie H Blumgart ${ }^{4}$, David S Klimstra ${ }^{3}$ and William R Jarnagin*4
}

\begin{abstract}
Address: ${ }^{1}$ Department of Surgery and Cell Biology, New York University School of Medicine, 550 First Avenue, New York, NY 10016, USA, ${ }^{2}$ Department of Biostatistics, Memorial Sloan-Kettering Cancer Center, 1275 York Avenue, New York, NY 1002, USA, ${ }^{3}$ Department of Pathology, Memorial Sloan-Kettering Cancer Center, 1275 York Avenue, New York, NY 1002, USA and ${ }^{4}$ Department of Surgery, Memorial Sloan-Kettering Cancer Center, 1275 York Avenue, New York, NY 10021, USA

Email: George Miller - george.miller@med.nyu.edu; Nicholas D Socci - soccin@mskcc.org; Deepti Dhall - Deepti.Dhall@cshs.org; Michael D'Angelica - dangelim@mskcc.org; Ronald P DeMatteo - dematter@mskcc.org; Peter J Allen - allenp01@mskcc.org; Bhuvanesh Singh - singhb@mskcc.org; Yuman Fong - fongy@mskcc.org; Leslie H Blumgart - Blumgarl@mskcc.org; David S Klimstra - Klimstrd@mskcc.org; William R Jarnagin* - jarnagiw@MSKCC.ORG

* Corresponding author
\end{abstract}

Published: 12 May 2009

Journal of Experimental \& Clinical Cancer Research 2009, 28:62 doi:10.1 186/1756-9966-28-62

This article is available from: http://www.jeccr.com/content/28/l/62

(c) 2009 Miller et al; licensee BioMed Central Ltd.

This is an Open Access article distributed under the terms of the Creative Commons Attribution License (http://creativecommons.org/licenses/by/2.0), which permits unrestricted use, distribution, and reproduction in any medium, provided the original work is properly cited.
Received: I February 2009

Accepted: 12 May 2009

\begin{abstract}
Background: The pathogenesis of biliary cancers is ill-defined. This study investigates changes in gene expression and copy number in biliary cancers and correlates these changes with anatomical site of origin, histopathology and outcome.

Methods: We performed gene expression and CGH analysis on 34 biliary tract cancer specimens. Results were confirmed by RT-PCR. Clinical-pathologic correlation was made using functional over-representation analysis of the top 100 mutations associated with each variable.

Results: There were 545 genes with altered expression in extrahepatic cholangiocarcinoma, 2,354 in intrahepatic cholangiocarcinoma, and I,28I in gallbladder cancer. Unsupervised hierarchical clustering analysis indicated there was no difference in the global gene expression patterns between each biliary cancer subgroup. CGH analysis revealed that short segments of chromosomes Ip, 3p, $6 q, 8 p, 9 p$, and $14 q$ were commonly deleted across all cancer subtypes. Commonly amplified regions included segments of Iq, 3q, 5p, 7p, 7q, 8q, and 20q. Over-representation analysis revealed an association between altered expression of functional gene groupings and pathologic features.
\end{abstract}

Conclusion: This study defined regions of the genome associated with changes in DNA copy number and gene expression in specific subtypes of biliary cancers. The findings have implications for identification of therapeutic targets, screening, and prognostication.

\section{Background}

Biliary tract cancers account for approximately $10-20 \%$ of hepatobiliary neoplasms. Approximately 9,000 cases of biliary tumors are diagnosed in the USA each year. Gall- bladder carcinoma (GBC) is the most common, accounting for $60 \%$ of cases [1]. The remaining $40 \%$ are cholangiocarcinomas and are further sub-classified as intrahepatic (IHC) when they arise from intrahepatic biliary 
radicles or extrahepatic (EHC) when they arise from the confluence of the main left and right hepatic ducts or distal in the bile ducts. The classification of biliary tract cancers into these anatomically-based subtypes has substantial clinical relevance, as risk factors, presentation, staging, and treatment varies for each $[2,3]$. Regardless of subtype, most patients with carcinoma of the biliary tract present with advanced disease, with median survival of approximately one to two years from the time of diagnosis [4-6].

Little is known regarding the genetic alterations in the biliary epithelium that lead to cancer. Studies have shown that biliary carcinogenesis may be related in-part to loss of heterozygosity at the loci of chromosomes $1 \mathrm{p}, 6 \mathrm{q}, 9 \mathrm{p}$, $16 \mathrm{q}$, and $17 \mathrm{p}$, and point mutations at the K-ras oncogene and the p-53 tumor suppressor gene $[7,8]$. Enhanced expression of VEGF in cholangiocarcinoma cells and localization of VEGF receptor-1 and receptor-2 in endothelial cells is thought to play a crucial role in tumor progression [9]. Clyclooxygenase-2 and c-erbB-2 are also overexpressed in cholangiocarcinoma [10]. In addition, interleukin-6 is important in the proliferation of malignant biliary epithelial cells $[11,12]$. Our recent work examining cell cycle-regulatory protein expression in biliary tract cancers revealed differentially expressed cell cycle-regulatory proteins based on tumor location and morphology, and an overlap in the pathogenesis of GBC and EHC was suggested [13].

The present study investigates alterations in gene expression and gene copy number in frozen tumor specimens from patients with GBC, IHC, and EHC. Gene expression results were correlated with comparative genomic hybridization (CGH) data by identifying transcriptional changes in the most highly unstable genomic regions. Additionally, the genetic findings were correlated with clinical disease characteristics and pathologic features.

\section{Methods}

\section{Patients and specimens}

Biliary tract cancers from 34 patients (13 IHC, 12 EHC, 9 $\mathrm{GBC}$ ) were snap-frozen and stored at $-80^{\circ} \mathrm{C}$. In addition 9 non-cancerous gallbladders and 9 non-cancerous bile duct controls were obtained from patients who had resections for diseases not involving the gallbladder or bile duct (in these patients the gallbladder or bile duct was removed for surgical access to other hepatobiliary or pancreatic structures). Each sample was re-examined histologically using H\&E-stained cryostat sections. Surrounding non-neoplastic tissue was dissected from the frozen block under $10 \times$ magnification and care was taken that at least $90 \%$ for remaining cells were cancerous. All studies were approved by the Memorial Sloan-Kettering IRB.

\section{RNA isolation, probe preparation, and expression microarray hybridization}

Total RNA was isolated from tissue using the DNA/RNA all prep kit (Qiagen, Germantown, Maryland, USA). Quality of RNA was ensured before labeling by analyzing 20-50 ng of each sample using the RNA 6000 NanoAssay and a Bioanalyzer 2100 (Agilent, Santa Clara, California, USA). Samples with a $28 \mathrm{~S} / 18 \mathrm{~S}$ ribosomal peak ratio of 1.8-2.0 and a RIN number $>7.0$ were considered suitable for labeling. RNA from one IHC specimen, two EHC specimens, and three cases of GBC failed to meet this standard and were discarded from the gene expression analysis. For the remaining samples, $2 \mu \mathrm{g}$ of total RNA was used for cDNA synthesis using an oligo-dT-T7 primer and the SuperScript Double-Stranded cDNA Synthesis Kit (Invitrogen, Carlsbad, California, USA). Synthesis, linear amplification, and labeling of cRNA were accomplished by in-vitro transcription using the MessageAmp aRNA Kit (Ambion, Austin, Texas, USA) and biotinylated nucleotides (Enzo Diagnostics, New York, USA). Ten micrograms of labeled and fragmented cRNA were then hybridized to the Human HG-U133A GeneChip (Affymetrix, Santa Clara, California, USA) at $45^{\circ} \mathrm{C}$ for 16 hours. Post hybridization staining, washing were processed according to manufacturer. Finally, chips were scanned with a high-numerical aperture and flying objective lens in the GS3000 scanner (Affymetrix). The image was quantified using GeneChip Operating Software (GCOS) 1.4 (Affymetrix).

\section{Array CGH profiling}

Genomic DNA was extracted using the DNA/RNA prep kit (Qiagen). DNA integrity was checked on a $1 \%$ agarose gel and was intact in all specimens except one case of EHC. 3 $\mu \mathrm{g}$ of DNA was then digested and labeled by random priming using RadPrime (Invitrogen) and Cy3 or Cy5dUTP. Labeled DNA was hybridized to $244 \mathrm{~K}$ CGH arrays (Agilent) for 40 hours at $60^{\circ} \mathrm{C}$. Slides were scanned and images quantified using Feature Extraction 9.1 (Agilent).

\section{Real-Time PCR}

1 ug of total RNA was reverse-transcribed using the Thermoscript RT-PCR system (Invitrogen) at $52^{\circ} \mathrm{C}$ for $1 \mathrm{~h} .20$ ng of resultant cDNA was used in a Q-PCR reaction using an iCycler (Biorad, Hercules, California, USA) and predesigned TaqMan ABI Gene expression Assays (Hs00270424_m1 for CCNB2, Hs00938777_m1 for CDC2, Hs00175938_m1 for CDKN1C, Hs01665258_m1 for DLC1, Hs01547109_m1 for FOSB, Hs99999032_m1 for IL6, s01118813_m1 for NR4A2, Hs00971643_g1 for SRD5A1, Hs01014001_m1 for STAT1, Hs00426591_m1 for TYMS, Hs00197374_m1 for UBD). Primers were chosen based on their ability to span the most 3' exon-exon junction. Amplification was carried for 40 cycles (95C for 
$15 \mathrm{sec}, 60 \mathrm{C}$ for $1 \mathrm{~min})$. To calculate the efficiency of the PCR reaction, and to assess the sensitivity of each assay, we also performed a 7 point standard curve (5, $1.7,0.56,0.19,0.062,0.021$, and $0.0069 \mathrm{ng}$ ). Amounts of target were interpolated from the standard curves and normalized to HPRT (Hs99999909_m1).

\section{Data Analysis}

Image files were quantified using GCOS 1.1 to generate the CEL files. These were normalized using the GC-RMA package from the Bioconductor toolkit (Bioconductor, Seattle, Washington State, USA). Expression values were log (base 2) transformed for all subsequent analysis. Unsupervised hierarchical clustering was done using a distance measure derived from the Pearson correlation (distance $=(1-\rho) / 2$ were $\rho$ is the correlation coefficient $)$ and average linkage options. To determine differentially expressed genes a variant of the t- and F-tests were used as implemented in the LIMMA toolkit (Bioconductor). To account for multiple-testing the False Discovery Rate (FDR) method was used. An FDR $<0.01$ was considered statistically significant. For clinicopathologic correlation, a functional over-representation analysis was done on the top 100 genes. $\mathrm{p}<0.001$ was considered significant.

For the array-CGH data, the raw images were quantified with the Agilent Feature Extraction program and normalized using a combination of intensity dependent and GCcontent dependent non-linear normalization procedure. To determine significant changes in copy number, the Circular Binary Segmentation algorithm [14] was used with alpha set to 0.001 . Segments that had a $\log 2$ ratio of intensity greater than a sample dependent threshold and a signal-to-noise ratio greater than 0.5 were considered either amplified or deleted.

\section{Results}

\section{Clinicopathologic Data}

Frozen tissue was analyzed from 34 patients who underwent surgery for biliary tract cancers between August 1993 and December 2005. 13 patients had IHC, 12 had EHC, either at the bile duct bifurcation or in the mid or distal bile duct, and 9 patients had tumors originating within the gallbladder. Selected clinicopathologic features are shown in Table 1 . The median age of patients was 64 (range 46-88) and 20 (59\%) patients were female. 31 (91\%) patients had margin-negative resections, two (6\%) patients had margin-positive resections, and one (3\%) patient underwent biopsy only.

At last follow-up, 10 (29\%) patients were alive without evidence of disease, $3(9 \%)$ patients were alive with recurrent disease and 19 (56\%) died as a result of their disease. One (3\%) patient died of an unrelated cause and one (3\%) patient was lost to follow-up. The median follow-up for surviving patients was 58 months (range 11-98). A review of pathologic features revealed that $6(18 \%)$ patients had poorly differentiated tumors, 11 (32\%) patients had evidence of lymph node invasion, 15 (44\%) had vascular invasion, and 15 (44\%) had perineural invasion. The median tumor size was $11.0 \mathrm{~cm}$ (range 6.0 21.0) for IHC, $2.1 \mathrm{~cm}$ (range 1.5 - 5.9) for EHC, and 4.7 $\mathrm{cm}$ (range 1.5 - 12.0) for GBC (Table 1).

\section{Gene Transcriptional Alterations in Biliary Carcinomas}

We analyzed alterations in gene expression in EHC, IHC, and GBC compared with non-cancerous bile duct or gallbladder controls using the Human Genome U133A GeneChip. Figure 1 depicts the 40 top ranking overexpressed and underexpressed genes for (a) extrahepatic cholangiocarcinoma, (b) IHC, and (c) GBC. Ranking was based on FDR values. Table 2 summarizes the extent of gene expression alterations for each type of biliary tract cancer. In the EHC specimens, differential expression was noted in 545 genes compared with 2,354 in IHC and 1,281 in GBC (See additional files 1, additional file 2, and additional file 3 ). There was a near equal distribution of overexpressed and underexpressed genes for each tumor type. However, higher fold changes in expression levels were seen more commonly with underexpressed genes. In particular, depending on cancer subtype, 16-22\% of genes with decreased expression had greater than 10-fold changes expression levels compared with controls. Conversely, only $2-12 \%$ of genes with increased expression had alterations of 10 -fold or greater (Table 2).

\section{Comparative Analysis of Biliary Cancer Subtypes}

Unsupervised hierarchical clustering analysis revealed that the three cancer subtypes did not cluster separately, implying that there was no difference in the global gene expression patterns between the biliary cancer subgroups. Figure $1 \mathrm{~d}$ depicts the top 40 up-regulated and down-regulated genes for all cancers combined versus the 18 control specimens. However, while the individual cancer subtypes did not cluster separately, there was unique differential expression of many genes compared with normal biliary epithelium in each cancer subtypes. The relationship of gene transcriptional changes among the three biliary cancer subtypes is depicted in a Venn diagram (Figure 1e). There was unique altered expression of 1633,80 , and 790 genes in IHC, EHC, and GBC, respectively. Overall, 165 probe sets were commonly differentially expressed in all 3 cancer types (See additional file 4). Selected commonly differentially expressed genes are listed in Table 3.

\section{Genomic Alterations in Biliary Carcinogenesis}

To better understand the molecular pathogenesis of biliary tract cancers we used an array based CGH analysis to detect chromosomal areas of DNA copy number gain (DNA copy number of 3 or greater) and loss (DNA copy 
Table I: Clinicopathologic features of biliary tract cancer patients in this study

\begin{tabular}{|c|c|c|c|c|c|c|c|c|c|}
\hline $\begin{array}{l}\text { Biliary } \\
\text { Cancer } \\
\text { Subtype }\end{array}$ & Age & Sex & $\begin{array}{l}\text { Lymph Node } \\
\text { Invasion }\end{array}$ & $\begin{array}{l}\text { Vascular } \\
\text { Invasion }\end{array}$ & $\begin{array}{l}\text { Perineural } \\
\text { Invasion }\end{array}$ & $\begin{array}{c}\text { Pathologic } \\
\text { Differentiation }\end{array}$ & Size $(\mathrm{cm})$ & $\begin{array}{l}\text { Follow-up } \\
\text { (months) }\end{array}$ & $\begin{array}{l}\text { Disease } \\
\text { Status }^{a}\end{array}$ \\
\hline Extrahepatic & 77 & $\mathrm{~F}$ & Present & Absent & Present & Poor & 2.0 & 42 & DOD \\
\hline Extrahepatic & 57 & $\mathrm{~F}$ & Present & Present & Present & Moderate & 1.5 & 61 & DOD \\
\hline Extrahepatic & 60 & $M$ & Present & Present & Present & Poor & 1.6 & 18 & DOD \\
\hline Extrahepatic & 78 & $M$ & Absent & Present & Present & Poor & 1.7 & 16 & NED \\
\hline Extrahepatic & 81 & $\mathrm{~F}$ & Absent & Absent & Absent & Well & 3.1 & 58 & AWD \\
\hline Extrahepatic & 75 & $M$ & Absent & Present & Absent & Moderate & 2.2 & 87 & AWD \\
\hline Extrahepatic & 77 & $\mathrm{~F}$ & Absent & Absent & Present & Moderate & 4.0 & 45 & DOD \\
\hline Extrahepatic & 56 & $M$ & Absent & Absent & Present & Moderate & 2.0 & 13 & DOD \\
\hline Extrahepatic & 67 & $\mathrm{~F}$ & Absent & Absent & Present & Moderate & 1.8 & 20 & DOD \\
\hline Extrahepatic & 56 & $M$ & Absent & Present & Present & Moderate & 4.8 & 40 & DOD \\
\hline Extrahepatic & 62 & $M$ & Absent & Absent & Absent & Well & 5.9 & 58 & NED \\
\hline Extrahepatic & 47 & $M$ & Absent & Absent & Present & Moderate & 2.3 & 6 & DOD \\
\hline Intrahepatic & 64 & $M$ & Absent & Absent & Absent & Moderate & 8.0 & 32 & DOD \\
\hline Intrahepatic & 66 & $\mathrm{~F}$ & Absent & Present & Absent & Moderate & 13.0 & 6 & DOD \\
\hline Intrahepatic & 63 & $M$ & Absent & Present & $\mathrm{n} / \mathrm{a}$ & Poor & 9.9 & 14 & DOD \\
\hline Intrahepatic & 56 & $M$ & Absent & Present & Absent & Moderate & 11.0 & 18 & DOD \\
\hline Intrahepatic & 70 & $M$ & Absent & Absent & $\mathrm{n} / \mathrm{a}$ & Moderate & 6.0 & 98 & NED \\
\hline Intrahepatic & 53 & $\mathrm{~F}$ & Absent & Present & Present & Moderate & 8.5 & 23 & DOD \\
\hline Intrahepatic & 60 & $\mathrm{~F}$ & Absent & Absent & Absent & Poor & 18.0 & 40 & DOD \\
\hline Intrahepatic & 68 & $\mathrm{~F}$ & Absent & Absent & Absent & Moderate & 12.0 & 33 & DOD \\
\hline Intrahepatic & 50 & $M$ & Absent & Absent & Absent & Well & 21.0 & 68 & NED \\
\hline Intrahepatic & 60 & $\mathrm{~F}$ & Absent & Absent & Absent & Moderate & 20.0 & 20 & DOD \\
\hline Intrahepatic & 58 & $M$ & Present & Present & Absent & Moderate & 9.0 & 38 & DOD \\
\hline Intrahepatic & 46 & $\mathrm{~F}$ & Present & Present & Absent & Moderate & 7.0 & 37 & NED \\
\hline Intrahepatic & 87 & $\mathrm{~F}$ & Present & Absent & Absent & Moderate & 14.0 & II & NED \\
\hline Gallbladder & 58 & $\mathrm{~F}$ & Present & Absent & Present & Moderate & 1.5 & $\mathrm{n} / \mathrm{a}$ & $\mathrm{n} / \mathrm{a}$ \\
\hline Gallbladder & 78 & $\mathrm{~F}$ & Absent & Absent & Absent & Moderate & 12.0 & 77 & NED \\
\hline Gallbladder & 79 & $\mathrm{~F}$ & Absent & Absent & Absent & Moderate & 9.0 & 62 & NED \\
\hline Gallbladder & 51 & $\mathrm{~F}$ & Present & Present & Present & Poor & 4.7 & 24 & AWD \\
\hline Gallbladder & 61 & $\mathrm{~F}$ & Present & Present & Present & Moderate & 2.0 & 1 & DUC \\
\hline Gallbladder & 88 & $\mathrm{~F}$ & Absent & $n / a^{b}$ & $\mathrm{n} / \mathrm{a}$ & Moderate & 8.7 & 2 & DOD \\
\hline Gallbladder & 68 & $\mathrm{~F}$ & Absent & $\mathrm{n} / \mathrm{a}$ & $\mathrm{n} / \mathrm{a}$ & Moderate & 3.5 & 82 & NED \\
\hline Gallbladder & 78 & $\mathrm{~F}$ & Present & Present & Present & Moderate & 9.0 & 3 & DOD \\
\hline Gallbladder & 78 & $M$ & Present & Present & Present & Moderate & 4.7 & 13 & NED \\
\hline
\end{tabular}

Table 2: Summary of transcription mutations in subtypes of biliary tract carcinoma

\begin{tabular}{llll}
\hline & Extrahepatic Cholangiocarcinoma & Intrahepatic Cholangiocarcinoma & Gallbladder Carcinoma \\
\hline Number of transcriptional changes & 545 & 2354 & 1281 \\
\hline Increased expression & 200 & 1286 & 479 \\
\hline Decreased expression & 345 & 1068 & 802 \\
\hline Increased > 20-fold & 3 & 10 & 26 \\
\hline Increased > 10-fold & 16 & 31 & 59 \\
\hline Decreased $>$ 20-fold & 22 & 88 & 72 \\
\hline Decreased $>10$-fold & 56 & 227 & 174 \\
\hline
\end{tabular}



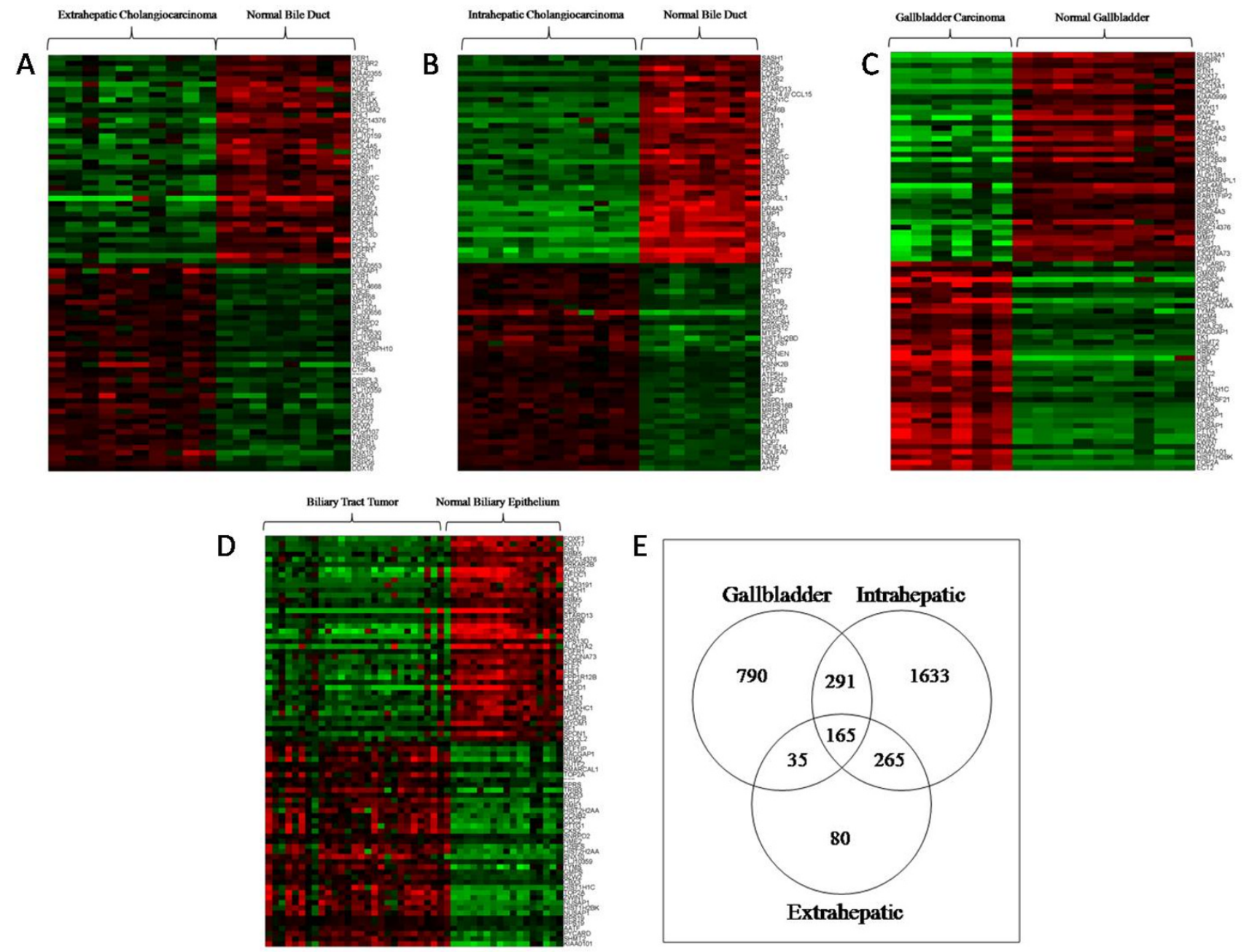

\section{Figure I}

Gene Expression Alterations in Biliary Tract Cancers. Heat maps showing the top 40 overexpressed (red) and top 40 underexpressed (green) genes for (a) EHC, (b) IHC, and (c) GBC. (d) All malignant subtypes were also combined for analysis and compared in terms of gene expression with benign bile duct and gallbladder controls. Genes were ranked based on FDR values. (e) A Venn diagram is used to depict the relationship of transcriptional changes among biliary cancer subtypes. There were 165 common genes with significantly altered expression in all three biliary tract cancer subtypes.

number of 0 or 1) in the GBC, IHC, and EHC specimens. Figure 2a depicts the chromosomal alterations for each individual cancer specimen while Figure $2 b-d$ represents cumulative summaries of the chromosomal changes for each cancer subtype. Cumulative chromosomal changes for all biliary tract cancers combined are shown in Figure $2 e$.

Overall, patients with GBC exhibited the greatest genomic instability while patients with IHC had the fewest amplifications and deletions. In particular, the mean number of chromosomal alterations per patient with GBC was 60.6 (range 17-110) with deletions (mean 35.0, range 9-55) more frequent than amplifications (mean 25.6, range 855). Patients with IHC had an average of 49.2 alterations (range 11-101) in DNA copy number with slightly more deletions (mean 26.9, range 8-80) than amplifications (mean 22.2, range 2-47). EHC specimens had an average of 43.8 chromosomal alterations (range 3-110) with an average of 22.5 deletions (range 1-61) and 21.4 amplifications (range 1-62). Moreover, there was considerable heterogeneity in the extent of chromosomal instability between patients even within specific cancer subtypes. For example, a number of patients within each cancer subtype had mutations in nearly every chromosomal arm while 
Table 3: Selected genes with significantly altered expression in all three biliary cancer subtypes with the fold-change $(\Delta)$ in expression

\begin{tabular}{|c|c|c|c|c|c|c|}
\hline$\Delta \mathrm{GB}$ & $\Delta$ Intra & $\Delta$ Extra & Gene Symbol & Gene Title & Chromosomal Location & Functional Pathway \\
\hline 58 & 11 & 11 & RRM2 & ribonucleotide reductase $M 2$ polypeptide & chr2p25-p24 & Nucleotide metabolism \\
\hline 41 & 6 & 10 & PTTG I & pituitary tumor-transforming $\mathrm{I}$ & $\operatorname{chr} 5 q 35.1$ & Cell cycle \\
\hline 26 & 9 & 7 & TYMS & thymidylate synthetase & chr|8p|l.32 & Nucleotide metabolism \\
\hline 19 & 4 & 5 & $\mathrm{CDC2}$ & Cell division cycle $2, \mathrm{GI}$ to $\mathrm{S}$ and $\mathrm{G} 2$ to $\mathrm{M}$ & $\operatorname{chrl0q21.1}$ & Cell cycle \\
\hline 18 & 4 & 7 & CCNB2 & cyclin B2 & $\operatorname{chr} 15 q 22.2$ & Cell cycle \\
\hline 12 & 3 & 4 & RACGAPI & Rac GTPase activating protein I & $\operatorname{chr} 12 q 13.12$ & SIP Signaling \\
\hline 6 & 5 & 4 & SHMT2 & serine hydroxymethyltransferase 2 (mitochondrial) & $\operatorname{chr}|2 q| 2-q \mid 4$ & Amino acid metabolism \\
\hline 3 & 3 & 3 & PPAT & phosphoribosyl pyrophosphate amidotransferase & $\operatorname{chr} 4 q 12$ & Purine metabolism \\
\hline 3 & 3 & 5 & MCM6 & MCM6 minichromosome maintenance deficient 6 & chr2q2l & Cell cycle \\
\hline 3 & 3 & 3 & GMPS & guanine monphosphate synthetase & chr3q24 & Nucleotide metabolism \\
\hline 2 & 2 & 2 & RPSI9 & ribosomal protein $\mathrm{SI} 9$ & $\operatorname{chr}|9 q| 3.2$ & Ribosomal protein \\
\hline 2 & 3 & 2 & $\mathrm{CB} \times 3$ & chromobox homolog 3 & chr7pI5.2 & Circadian exercise \\
\hline 2 & 3 & 2 & EIF2AKI & $\begin{array}{l}\text { eukaryotic translation initiation factor 2-alpha } \\
\text { kinase I }\end{array}$ & chr7p22 & Translation factor \\
\hline 2 & 2 & 2 & EPRS & glutamyl-prolyl-tRNA synthetase & $\operatorname{chrlq} 4 \mathrm{I}-\mathrm{q} 42$ & Glutamate metabolism \\
\hline 2 & 2 & 2 & PARPI & poly (ADP-ribose) polymerase family, member I & $\operatorname{chrlq41-q42}$ & Apoptosis \\
\hline 2 & 2 & 2 & SNRPD2 & $\begin{array}{l}\text { small nuclear ribonucleoprotein D2 polypeptide } \\
16.5 \mathrm{kDa}\end{array}$ & $\operatorname{chr} 19 q 13.2$ & mRNA processing \\
\hline-2 & -2 & -2 & UBE2G2 & $\begin{array}{l}\text { ubiquitin-conjugating enzyme E2G } 2 \\
\text { (UBC7 homolog) }\end{array}$ & chr2I q22.3 & Proteolysis \\
\hline-2 & -2 & -2 & HNRPHI & Heterogeneous nuclear ribonucleoprotein $\mathrm{HI}$ & $\operatorname{chr} 5 q 35.3$ & mRNA processing \\
\hline-2 & -3 & -3 & SUII & putative translation initiation factor & $\operatorname{chr} 17 q 21.2$ & Translation factor \\
\hline-3 & -4 & -3 & RBM5 & RNA binding motif protein 5 & chr3p2I.3 & mRNA processing \\
\hline-3 & -2 & -2 & SFRS5 & splicing factor, arginine/serine-rich 5 & $\operatorname{chrl} 4 \mathrm{q} 24$ & mRNA processing \\
\hline-3 & -3 & -3 & BCL2L2 & BCL2-like 2 & $\operatorname{chr}|4 q||.2-q| 2$ & Apoptosis \\
\hline-4 & -10 & -7 & CDKNIC & cyclin-dependent kinase inhibitor IC (p57, Kip2) & chrllpI5.5 & GI to $S$ cell cycle \\
\hline-4 & -8 & -5 & ZNF423 & zinc finger protein 423 & $\operatorname{chrl6q12}$ & TGF- $\beta$ signaling \\
\hline-4 & -3 & -3 & $A C A C B$ & acetyl-Coenzyme A carboxylase beta & $\operatorname{chr} 12 q 24.11$ & Fatty acid synthesis \\
\hline-4 & -4 & -3 & RBM5 & RNA binding motif protein 5 & chr3p2I.3 & mRNA processing \\
\hline-5 & -7 & -5 & PRKAR2B & $\begin{array}{l}\text { protein kinase, cAMP-dependent, regulatory, type } \\
\text { II, beta }\end{array}$ & chr7q22 & G protein signaling \\
\hline-5 & -4 & -4 & $\mathrm{ACACB}$ & acetyl-Coenzyme A carboxylase beta & $\operatorname{chr} 12 \mathrm{q} 24.11$ & Fatty acid synthesis \\
\hline-6 & -4 & -4 & ITGA7 & integrin, alpha 7 & $\operatorname{chrl} 2 q 13$ & Cellular adhesion \\
\hline-6 & -7 & -5 & RGS2 & regulator of G-protein signaling 2, $24 \mathrm{kDa}$ & chrlq3। & Calcium regulation \\
\hline-6 & -9 & -5 & KLF9 & Kruppel-like factor 9 & chr9ql3 & Circadian exercise \\
\hline-7 & -7 & -7 & RPS6KA2 & ribosomal protein $\mathrm{S} 6$ kinase, $90 \mathrm{kDa}$, polypeptide 2 & chr6q27 & Ribosomal protein \\
\hline-7 & -15 & -10 & ANK2 & ankyrin 2, neuronal & $\operatorname{chr} 4 q 25-q 27$ & Ribosomal protein \\
\hline-8 & -5 & -6 & $\mathrm{ACACB}$ & acetyl-Coenzyme A carboxylase beta & $\operatorname{chr} 12 q 24.11$ & Fatty acid synthesis \\
\hline-10 & -4 & -4 & MYOMI & myomesin I (skelemin) 185 kDa & chr|8p|I.32-p| I.3I & Muscle contraction \\
\hline-11 & -13 & -8 & ITGA7 & integrin, alpha 7 & $\operatorname{chr}|2 q| 3$ & Cellular adhesion \\
\hline-13 & -27 & -14 & CDKNIC & Cyclin-dependent kinase inhibitor IC (p57, Kip2) & chrllpl5.5 & GI to $S$ cell cycle \\
\hline-61 & -27 & -26 & ALDHIA2 & aldehyde dehydrogenase I family, member A2 & $\operatorname{chr} 15 q 21.3$ & Metabolism/Biosynthesis \\
\hline-67 & -20 & -7 & CNNI & calponin I, basic, smooth muscle & chrl9p|3.2-pl3.1 & Muscle contraction \\
\hline-85 & -51 & -18 & CESI & carboxylesterase I & $\operatorname{chr} 16 q 13-q 22.1$ & Irinotecan pathway \\
\hline-102 & -30 & -24 & DES & desmin & chr2q35 & Muscle contraction \\
\hline
\end{tabular}

other patients with the same tumor type had minimal structural changes in their entire genome (Figure 2a).

While the cumulative pattern of chromosomal alterations was highly variable, there appeared to be selected chromosomal regions that were commonly altered across all cancer subtypes. For example, a short segment of chromosome $1 \mathrm{p}$ was deleted in greater than $75 \%$ of patients with GBC and IHC and nearly 50\% of patients with EHC. Similarly, segments of chromosomes 3p, 6q, 8p, 9p, and 14q were commonly deleted across subtypes of biliary cancers. Commonly amplified regions across cancer types include segments of 1q, 3q, 5p, 7p, 7q, 8q, and 20q (Figure 2a-e).

\section{Analysis of Transcriptional Changes in Commonly Unstable Genomic Regions}

To further elucidate the pathogenesis of biliary tract cancers, we integrated the array based CGH data with our gene expression profiling with by identifying gene expression alterations in regions of highest genomic instability. 
A

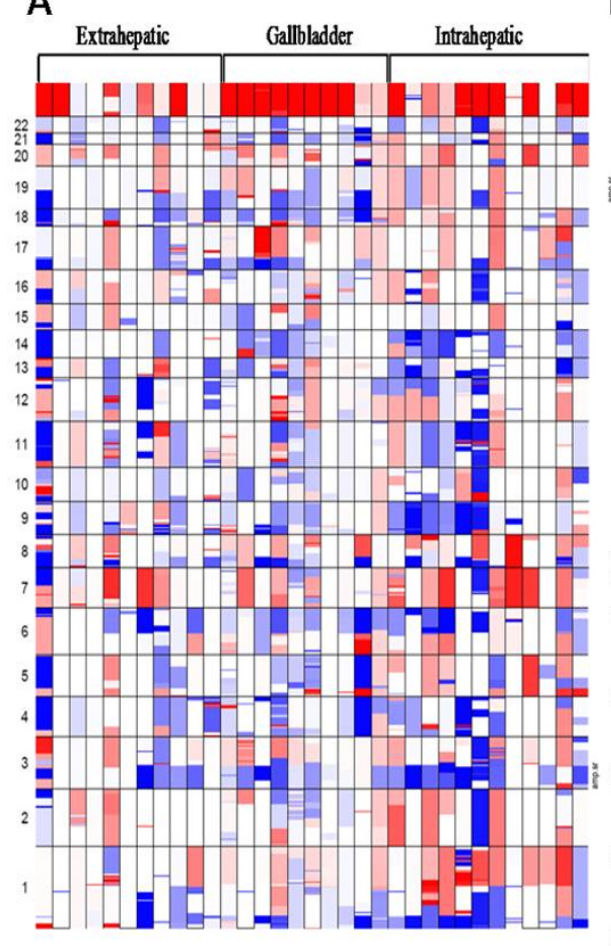

B

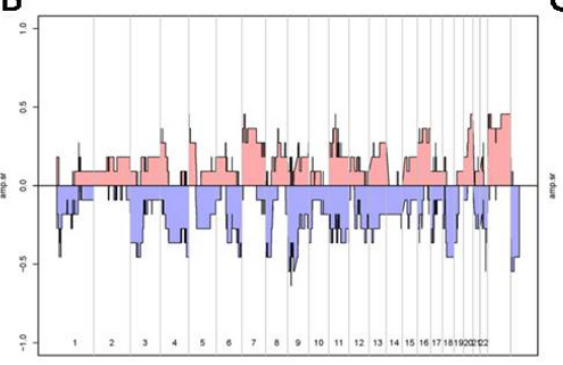

C

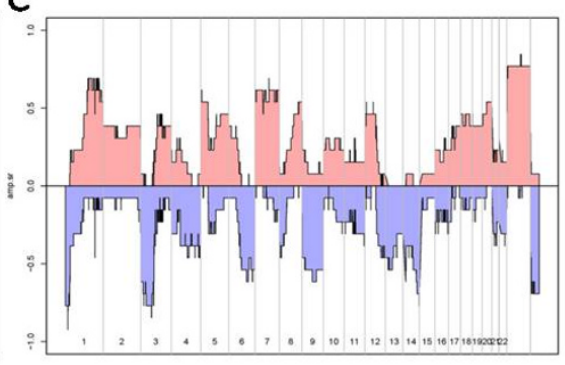

D

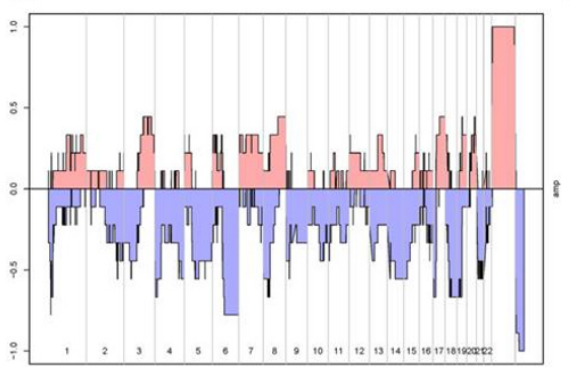

$E$

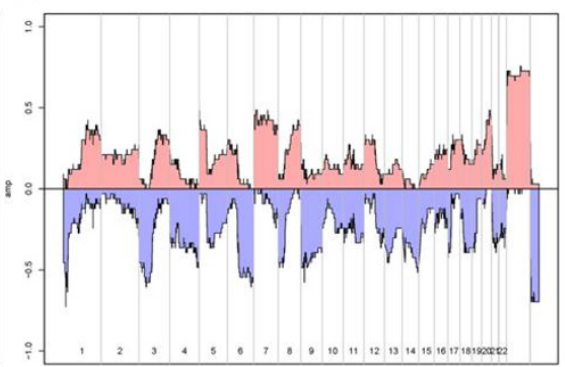

Figure 2

Chromosomal Structural Mutations in Biliary Tract Cancers. (a) A cumulative depiction of the copy number changes across the genome for all biliary cancer specimens is shown. Chromosomal number is listed on the left. Amplification is depicted in red and deletion in blue. White is unchanged from genomic DNA controls. Increased amplification or deletion within a cancer specimen is reflected in increased color intensity. The percentage of patient specimens that have either amplifications or deletions at each chromosomal loci is shown for (b) EHC, (c) IHC, (d) GBC, and (e) all biliary tract cancers combined.

To this end, we investigated the gene expression changes in regions of the genome for which greater than $40 \%$ of patients had either chromosomal gains or losses in each cancer subtype (See additional files 5, additional file 6 and additional file 7). Selected alterations in gene expression within these unstable genomic regions are shown in Table 4. Analysis of this data reveals that, as expected, a positive correlation could be made between chromosomal deletion and the loss of gene expression. Conversely, there were no instances of increased gene transcription in regions of chromosomal deletion. However, in regions of chromosomal amplification, both increased and decreased gene transcription were seen with similar frequency.

\section{Validation of Findings}

The Affymetrix U133A gene expression array data were both internally and externally validated. First, a large number of gene transcripts were represented by more than one probe set in the array. In each case, the different probes for each detected similar expression levels of transcript (See additional files 1, additional file 2, and addi- tional file 3). This includes genes with altered expression in EHC (i.e. CDKN1C, NR4A3, RBM5, SASH1), IHC (ADH1B, GREM1, MCM4, NR4A2), and GBC (HIST2H2AA, NUSAP1 RPS10, RPS19).

In addition, to externally validate our data, selected differentially expressed genes were measured for transcript levels in biliary carcinoma specimens and in normal biliary epithelial controls using quantitative reverse transcriptase PCR. We assayed 11 genes with differing biologic functions and involvement in diverse molecular pathways but with known importance in carcinogenesis. These included genes which were overexpressed in EHC (SRDA21, STAT1, UBD, TYMS), underexpressed in EHC (FOSB, CDKN1C, IL6), overexpressed in IHC (SRDA21, STAT1, UBD, TYMS), underexpressed in IHC (DLC1, NR4A2, ILG), and overexpressed in GBC (UBD, TYMS, CDC2, CCNB2). PCR data was normalized to HPRT which was expressed at similar levels in both the cancerous and the control biliary epithelium (not shown). Results are shown in Figures (3a-f, 4g-k) and, for each gene tested, confirm the Affymetrix U133A gene expression array data. The array- 
Table 4: Selected changes in gene expression in commonly amplified or deleted regions of the genome for all biliary tract cancer specimens

\begin{tabular}{|c|c|c|c|c|c|}
\hline Chromosomal Location & $\begin{array}{c}\text { \% Amplified (+) or } \\
\text { Deleted (-) }\end{array}$ & Fold Change & Gene Title & Gene Symbol & Functional Properties \\
\hline chr7pll & $+42 \%$ & 6.5 & IGF-II mRNA-binding protein 3 & IMP-3 & RNA processing \\
\hline chr7p/3-p/2 & $+45 \%$ & 3.6 & $\begin{array}{l}\text { insulin-like growth factor } \\
\text { binding protein } 3\end{array}$ & IGFBP3 & Regulation of cell growth \\
\hline chr5pl5.33 & $+42 \%$ & 3.5 & $\begin{array}{l}\text { thyroid hormone receptor } \\
\text { interactor } 13\end{array}$ & TRIPI3 & Regulation of transcription \\
\hline chr20q|3.32 & $+45 \%$ & 3.5 & RAEI RNA export I homolog & RAEI & mRNA-nucleus export \\
\hline chr7p2I.I & $+48 \%$ & 3.2 & $\begin{array}{l}\text { basic leucine zipper and W2 } \\
\text { domains } 2\end{array}$ & BZW2 & Translation initiation factor \\
\hline chr7q22.I & $+42 \%$ & 3.0 & $\begin{array}{l}\text { origin recognition complex, } \\
\text { subunit } 5 \text {-like }\end{array}$ & ORC5L & DNA replication initiation \\
\hline $\operatorname{chr} 20 q \mid 3.3$ & $+42 \%$ & 2.7 & ribosomal protein S2I & RPS2I & Protien biosysthesis \\
\hline chr7pl5 & $+42 \%$ & 2.6 & oxysterol binding protein-like 3 & OSBPL3 & Steroid metabolism \\
\hline chr7pl5-pl3 & $+42 \%$ & 2.5 & $\begin{array}{l}\text { v-ral simian leukemia viral } \\
\text { oncogene homolog } A\end{array}$ & RALA & $\begin{array}{l}\text { GTPase mediated signal } \\
\text { transduction }\end{array}$ \\
\hline $\operatorname{chr} 20 q \mid 3.2$ & $+48 \%$ & -6.9 & docking protein 5 & DOK5 & Insulin receptor binding \\
\hline chr7qli.2 & $+42 \%$ & -7.8 & CD36 antigen & CD36 & Lipid metabolism \\
\hline chr7q21.I & $+42 \%$ & -7.9 & $\begin{array}{l}\text { ATP-binding cassette, sub- } \\
\text { family B, member I }\end{array}$ & $A B C B I$ & Cell surface transport \\
\hline chr7p2I & $+45 \%$ & -9.1 & interleukin 6 & IL6 & Acute phase response \\
\hline chr20q I I.23 & $+42 \%$ & -10.0 & $\begin{array}{l}\text { myosin, light polypeptide } 9, \\
\text { regulatory }\end{array}$ & MYL9 & $\begin{array}{l}\text { Regulation of muscle } \\
\text { contraction }\end{array}$ \\
\hline chr7q31-q32 & $+42 \%$ & -10.9 & $\begin{array}{l}\text { solute carrier family } 13, \\
\text { member I }\end{array}$ & SLCI3AI & Ion transport \\
\hline chr20q13.13 & $+45 \%$ & -14.7 & prostaglandin 12 synthase & PTGIS & Prostaglandin biosynthesis \\
\hline chr7q31 & $+42 \%$ & -38.1 & $\begin{array}{l}\text { solute carrier family } 26 \text {, } \\
\text { member } 3\end{array}$ & SLC26A3 & Transcription factor activity \\
\hline chr6q22.I & $-55 \%$ & -46.2 & phospholamban & PLN & Calcium ion transport \\
\hline chr9q22 & $-42 \%$ & -41.0 & osteoglycin & OGN & Growth factor activity \\
\hline chr6q24-q25 & $-58 \%$ & -19.2 & A kinase anchor protein 12 & AKAPI 2 & Signal transduction \\
\hline $\operatorname{chr} 14 q 24.3$ & $-42 \%$ & -17.1 & $\begin{array}{l}\text { v-fos FBJ murine osteosarcoma } \\
\text { viral oncogene homolog }\end{array}$ & FOS & DNA methylation \\
\hline chrl4q32.I & $-45 \%$ & -13.6 & fibulin 5 & FBLN5 & Cell-matrix adhesion \\
\hline chr3p26-p25 & $-45 \%$ & -10.0 & $\begin{array}{l}\text { inositol I,4,5-triphosphate } \\
\text { receptor, type I }\end{array}$ & ITPRI & Cation transport \\
\hline chr3pl3 & $-52 \%$ & -9.2 & $\begin{array}{l}\text { PDZ domain containing RING } \\
\text { finger } 3\end{array}$ & PDZRN3 & Protein ubiquitination \\
\hline chr3p2I.I & $-58 \%$ & -8.9 & TU3A protein & TU3A & Regulation of cell growth \\
\hline $\operatorname{chrl4q32.I}$ & $-48 \%$ & -8.5 & $\begin{array}{l}\text { serine proteinase inhibitor, } \\
\text { clade } A \text {, member } 5\end{array}$ & SERPINA5 & Endopeptidase inhibitor \\
\hline chr3p22-p21.3 & $-58 \%$ & -8.5 & $\begin{array}{l}\text { C-type lectin domain family } 3 \text {, } \\
\text { member B }\end{array}$ & CLEC3B & Skeletal development \\
\hline chr9p/3.2-p|3.I & $-42 \%$ & -8.3 & tropomyosin 2 & TPM2 & Muscle development \\
\hline $\operatorname{chrl} 4 \mathrm{q} 32$ & $-48 \%$ & -8.1 & delta-like I homolog & DLKI & Calcium ion binding \\
\hline chr6q27 & $-58 \%$ & -6.5 & $\begin{array}{l}\text { ribosomal protein S6 kinase, } 90 \\
\text { kDa, polypeptide } 2\end{array}$ & RPS6KA2 & Amino acid phosphorylation \\
\hline chr6q24-q25 & $-52 \%$ & -6.2 & $\begin{array}{l}\text { pleiomorphic adenoma gene- } \\
\text { like I }\end{array}$ & PLAGLI & Regulation of transcription \\
\hline chr9p/3-p/2 & $-42 \%$ & -5.8 & $\begin{array}{l}\text { reversion-inducing-cysteine-rich } \\
\text { protein with kazal motifs }\end{array}$ & RECK & Cell cycle regulation \\
\hline chr3p2I.2-p2I.I & $-61 \%$ & -5.4 & aminomethyltransferase & AMT & Glycine catabolism \\
\hline chr6pter-qter & $-48 \%$ & -5.4 & transcription factor 21 & TCF2I & Regulation of transcription \\
\hline $\operatorname{chr} 9 q 13$ & $-42 \%$ & -5.1 & Kruppel-like factor 9 & KLF9 & Regulation of transcription \\
\hline chr6q23 & $-48 \%$ & -3.8 & $\begin{array}{l}\text { serum/glucocorticoid regulated } \\
\text { kinase }\end{array}$ & SGK & Amino acid phosphorylation \\
\hline chr3p26-p25 & $-45 \%$ & -3.6 & $\begin{array}{l}\text { inositol I,4,5-triphosphate } \\
\text { receptor, type I }\end{array}$ & ITPRI & Cell cycle regulation \\
\hline chrlp36.I3-p36.II & $-55 \%$ & -3.2 & $\begin{array}{l}\text { neuroblastoma, suppression of } \\
\text { tumorigenicity I }\end{array}$ & NBLI & calcium ion transport \\
\hline chr6q22 & $-55 \%$ & -2.6 & $\begin{array}{l}\text { mannosidase, alpha, class IA, } \\
\text { member I }\end{array}$ & MANIAI & Carbohydrate metabolism \\
\hline chr3p22 & $-48 \%$ & -2.5 & $\begin{array}{l}\text { transforming growth factor, } \\
\text { beta receptor II }\end{array}$ & TGFBR2 & $\begin{array}{l}\text { Regulation of cell } \\
\text { proliferation }\end{array}$ \\
\hline
\end{tabular}


based CGH results were internally validated by correlation of the $\mathrm{X}$ chromosome copy number with patient gender.

\section{Correlation of Gene Expression Profiles with Clinicopathologic Features}

To determine whether certain clinicopathologic features are associated with specific gene expression changes in biliary carcinomas, we performed over-representation analyses by determining whether certain functional gene categories were over-represented among the top 100 ranking genes (by FDR) with altered expressing in patients with specific clinicopathologic features. Altered expression of genes associated with functional categories related to ribosomal structure, cellular and protein biosynthesis and cellular metabolism were significantly associated with high grade tumors (See additional file 8). Similarly, a strong correlation could be made between vascular invasion and mutated expression of genes involved with electron transport and metabolism (See additional file 9). Perineural invasion was correlated with altered expression of genes in the functional categories associated with mitochondrial structure and electron transport (See additional file 10). There was no significant association between gene expression patterns and lymph node invasion. Similarly, we did not find a significant correlation between functional gene category over-representation and survival.

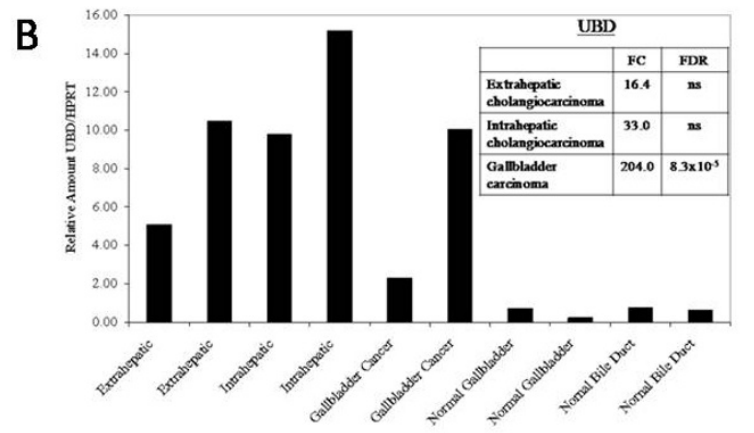

C
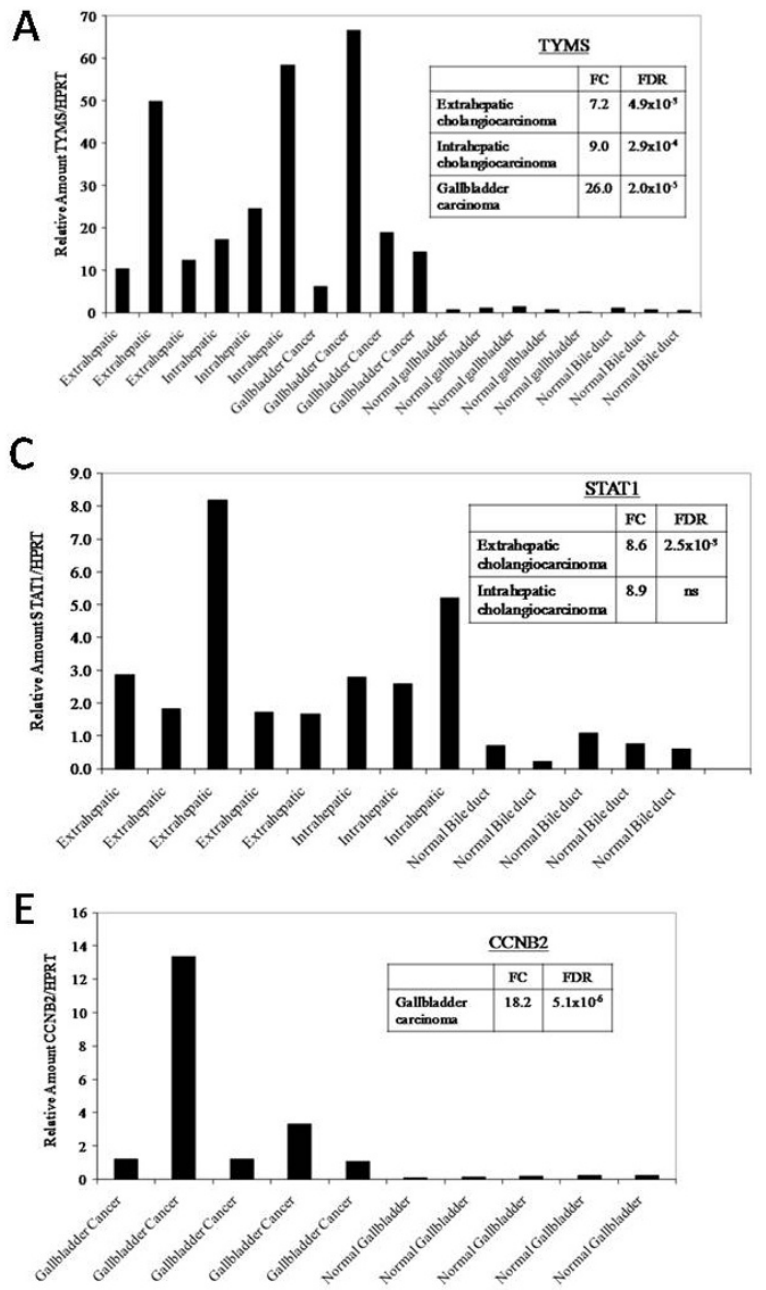

D

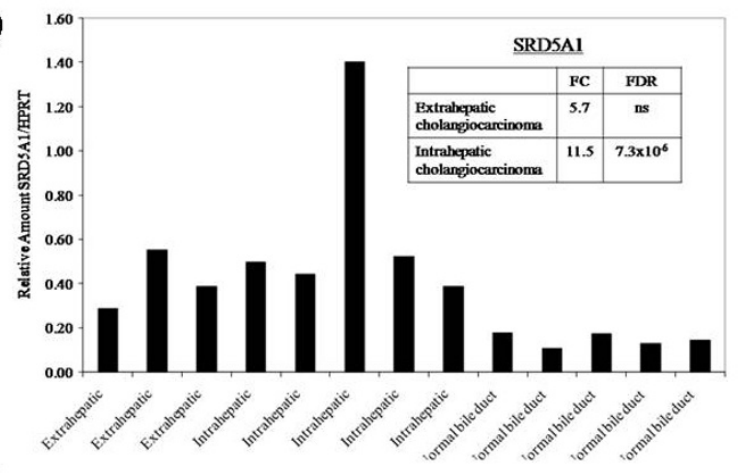

$\mathbf{F}$

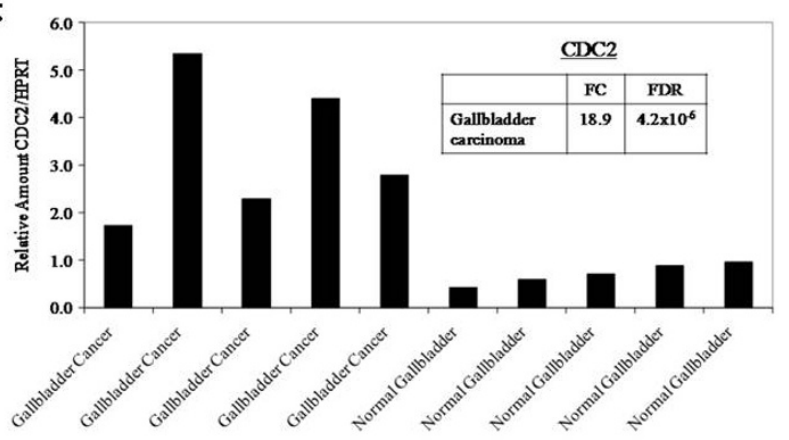

Figure 3

Real-Time PCR Based Validation of Gene Expression Findings. To confirm the gene expression changes in biliary tract cancers identified on microarray analysis, selected genes were tested in tumor and control specimens by RT PCR and normalized to HRPT which is similarly expressed in tumors and normal biliary epithelia. Results are shown for (a) TYMS, (b) UBD, (c) STATI, (d) SRD5AI, (e) CCNB2, (f) CDC2. 


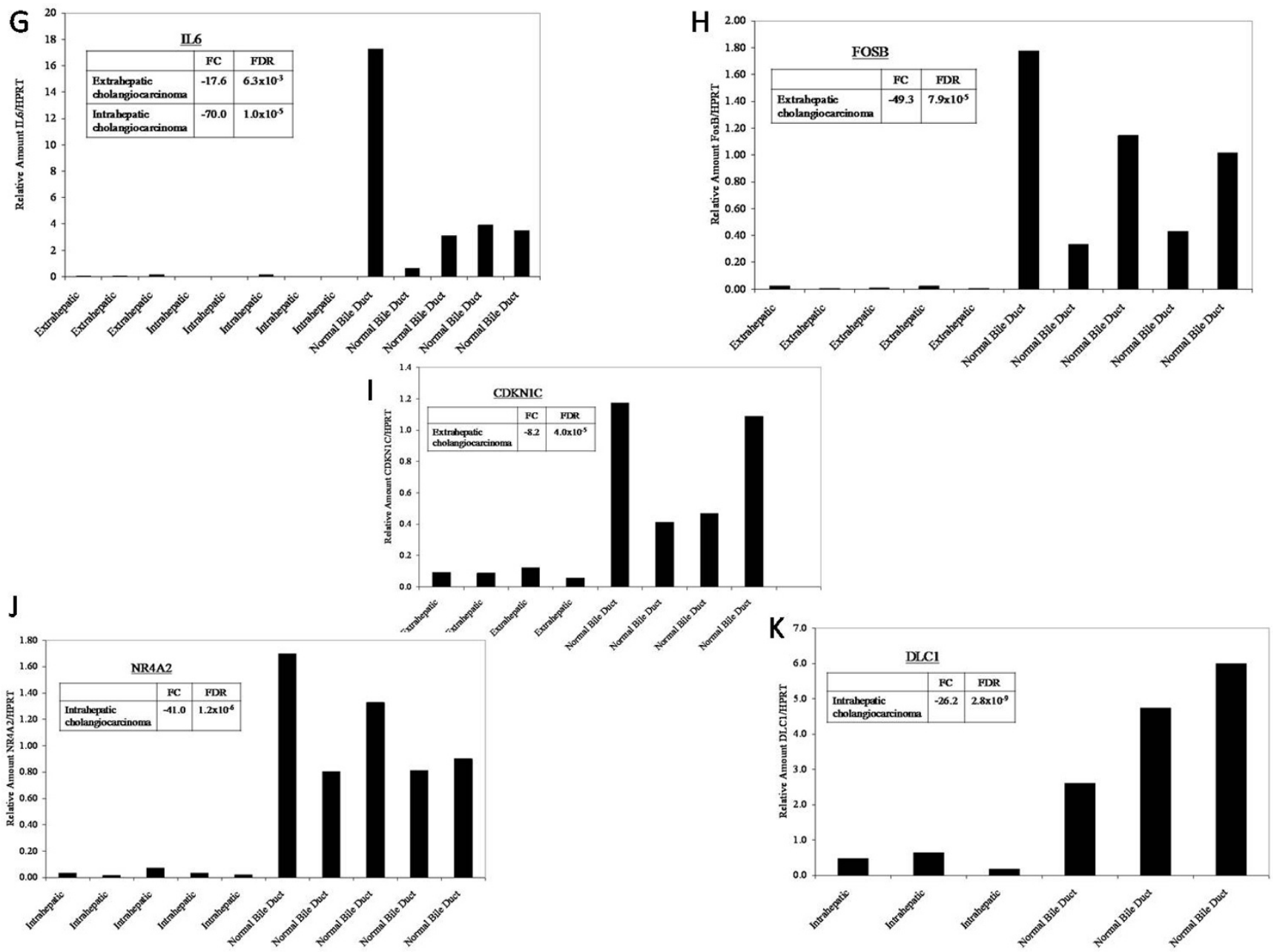

Figure 4

Real-Time PCR Based Validation of Gene Expression Findings. To confirm the gene expression changes in biliary tract cancers identified on microarray analysis, selected genes were tested in tumor and control specimens by RT PCR and normalized to HRPT which is similarly expressed in tumors and normal biliary epithelia. Results are shown for (g) IL6, (h) FOSB, (i) CDKNIC, (j) NR4A2, and (k) DLC.

\section{Discussion}

The molecular pathogenesis of biliary tract cancers is poorly understood. By performing immunohistochemical analysis of more than 125 surgically resected cases of biliary tract carcinoma, we have previously shown altered cell cycle regulatory protein expression in biliary tact cancers [13]. Our current findings also show mutated expression of a large number of cell cycle regulators including $U B D, B C L 2 L 2, C D C 2, M C M 2$, and CDKN1C in all subtypes. Similarly, Kang et al. [15] found that expression of G1-S modulators were commonly mutated in 42 cases of IHC. Total loss of p16, p27, and Rb were detected at rates of in 36\%, 31\%, 12\%, respectively, in cancer specimens. Furthermore, in the above study, even in 7 of 13 cases of biliary dysplasia, without frank carcinoma, abnormal expression of p53, cyclin D1 or p16 was detected. Kim et al. [16] reported that the mutation of the p53, p16, and Kras genes occurred at rates of $36 \%, 31 \%$ and $20 \%$, respectively, in GBC. A further finding of the above study was that $100 \%$ of GBCs and $80 \%$ of adenomas displayed loss of heterozygosity at a minimum of one locus which is consistent with our CGH results. Chang et al. [17] studied loss of heterozygosity in 32 cases of GBC and 11 cases of dysplasia. Loss of one allele was identified on chromosomes $5 \mathrm{q}(55 \%)$ and $17 \mathrm{p}(40 \%)$ in the dysplastic cases and on chromosomes 3p (52\%), 5q (66\%), 9p (52\%), and $17 \mathrm{p}(58 \%)$ in the carcinomas. Loss of heterozygosity on multiple chromosomes was significantly more fre- 
quent in patients with metastatic disease than in cases without metastases. In the current report, we similarly found that segments of $3 p$ and $9 p$ were commonly deleted across all subtypes of biliary cancers. However, we additionally discovered that segments of $6 \mathrm{q}, 8 \mathrm{p}$, and $14 \mathrm{q}$ were commonly deleted across subtypes of biliary cancers

There is increasing evidence that overexpression of tyrosine kinase growth factor receptors such as ErbB-2, epidermal growth factor receptor (EGFR), and Met play important roles in the development of biliary tract carcinomas. Nakasawa et al. [18] studied tyrosine kinase receptor proteins expression by in 221 biliary tract carcinomas and found that overexpression of ErbB-2 was found in $16 \%$ of carcinomas of the gallbladder and a slightly lower percentage of extrahepatic bile duct tumors. ErbB-2 gene amplification was present in $79 \%$ of cases. Overexpression of EGFR was found in $8 \%$ of tumors and was also associated with a high frequency of gene amplification $(77 \%)$. Met overexpression was most frequent in IHC $(21.4 \%)$ but was not associated with gene amplification. Microsatellite instability also appears to be a critical factor in selected cases of biliary carcinogenesis. Roa et al. [19] performed microsatellite analysis on 59 frozen GBC specimens using 13 different markers. They found evidence of microsatellite instability in equal proportions in early and late cancers, and it was also found in premalignant lesions, indicating that inactivation of mismatch repair genes occurs early in gallbladder carcinogenesis.

In addition to finding that a large proportion of differentially expressed genes in this study involved in cell cycle regulation and apoptosis, we also discovered a disproportionate number of mutated genes that control transcriptional regulation, RNA procession, cellular signaling, or are involved with cytoskeletal structure, extracellular matrix, and cellular adhesion. Differentially expressed genes involved with transcriptional regulation include STAT1, NARG1, HOXC6, and MMP11. Important genes involved with signal transduction with altered expression include CXCL5, ECT2, GPRC5A, MELK, and CKS2. Dysregulated genes involved with cytoskeleton, extracellular matrix and cellular adhesion include ITGA7, LAMB3, CECAM5, KRT6B, and CLDN18.

The findings of the present study will serve as a resource for other investigators in this area as we have indentified many potential targets for therapeutic intervention. As an example, we found that TYMS, which encodes an enzyme that catalyzes 5-fluorouracil, was overexpressed 7.2 26.0-fold depending on biliary cancer subtype. TYMS expression is correlated inversely with clinical response to 5 -fluorouracil-based chemotherapy and the overexpression may explain the futility of 5-fluorouracil-based chemotherapy for biliary carcinomas [20].
We also found that a number of genes in the ubiquitin pathway had altered expression in each cancer subtypes. For example, more than 20 ubiquitin-related genes had significantly altered expression IHC. In GBC, UBD was overexpressed more than 200-fold and UBE2C was overexpressed nearly 15 -fold. Ubiquitin and ubiquitin-like proteins are signaling messengers that regulate a variety of cellular processes including cell proliferation, cell cycle regulation, DNA repair, and apoptosis. There is accumulating evidence that deregulation of this pathway as a result of mutations or altered expression of ubiquitylating or de-ubiquitylating enzymes as well as of Ub-binding proteins affect crucial mediators of these functions and are underlie the pathogenesis of several human malignancies [21]. A variety of inhibitors of the ubiquitin system are currently being experimentally tested in clinical trials with promising early results [22]. These data suggests these inhibitors may have applicability as adjuvants in treating patients with biliary tract carcinomas.

Another promising target uncovered in this report is STAT-1 which was overexpressed nearly 9-fold in cases of cholangiocarcinoma. The Signal Transducers and Activator of Transcription (STAT) proteins regulate many aspects of cell growth, survival and differentiation. The transcription factors of this family are activated by the Janus Kinase JAK and dysregulation of this pathway has been observed in primary tumors and leads to increased angiogenesis, metastases, enhanced survival of tumors, and immunosuppression $[23,24]$. A number of JAK/STAT pathway inhibitors are being tested in pre-clinical studies and their application to cancers of the biliary tract may prove promising [25].

\section{Conclusion}

Both gene expression and CGH data support an overlapping pathogenetic mechanism for all subsets of biliary tract cancers. However, exceptional diversity of mutational findings between individual patient specimens is also apparent. Functional over-representation analysis revealed a significant association between altered expression of genes involved with regulation of cellular metabolism and biosynthesis and high pathologic grade. Vascular invasion was associated with mutated expression of genes involved with electron transport and cellular metabolism. CGH analysis revealed that short segments of chromosomes $1 \mathrm{p}, 3 \mathrm{p}, 6 \mathrm{q}, 8 \mathrm{p}, 9 \mathrm{p}$, and $14 \mathrm{q}$ were commonly deleted across all cancer subtypes while commonly amplified regions included segments of 1q, 3q, 5p, 7p, 7q, 8q, and $20 \mathrm{q}$. The data also offer opportunities to uncover potential targets for experimental therapeutics.

\section{Competing interests}

The authors declare that they have no competing interests. 


\section{Authors' contributions}

GM carried out the conception and design, acquisition, analysis, and interpretation of data, drafting of manuscript, critical review, and final approval. NDS contributed in the conception and design, analysis and interpretation of data, critical review, and final approval. DD contributed in the acquisition of data, and final approval. MD contributed in the conception and design, critical review, and final approval. RPD contributed in the conception and design, critical review, and final approval. PJA contributed in the conception and design, critical review, and final approval. BS contributed in the conception and design, critical review, and final approval. YF contributed in the conception and design, critical review, and final approval. LHB contributed in the conception and design, critical review, and final approval. DSK contributed in the conception and design, analysis and interpretation of data, critical review, and final approval. WRJ carried out the conception and design, analysis and interpretation of data, drafting of manuscript, critical review, and final approval. All authors have read and approved the final manuscript.

\section{Additional material}

\section{Additional File 1}

Gene Expression Changes in Extrahepatic Cholangiocarcinoma. Click here for file

[http://www.biomedcentral.com/content/supplementary/17569966-28-62-S1.xls]

\section{Additional File 2}

Gene Expression Changes in Intrahepatic Cholangiocarcinoma. Click here for file

[http://www.biomedcentral.com/content/supplementary/17569966-28-62-S2.xls]

\section{Additional File 3}

Gene Expression Changes in Gallbladder Cancer.

Click here for file

[http://www.biomedcentral.com/content/supplementary/17569966-28-62-S3.xls]

\section{Additional File 4}

Commonly Differentially Expressed Genes in All Biliary Cancer Subtypes.

Click here for file

[http://www.biomedcentral.com/content/supplementary/1756-

9966-28-62-S4.xls]

\section{Additional File 5}

Gene Expression Changes in Unstable Genomic Regions for Extrahepatic Cholangiocarcinoma.

Click here for file

[http://www.biomedcentral.com/content/supplementary/17569966-28-62-S5.xls]

\author{
Additional File 6 \\ Gene Expression Changes in Unstable Genomic Regions for Intrahe- \\ patic Cholangiocarcinoma. \\ Click here for file \\ [http://www.biomedcentral.com/content/supplementary/1756- \\ 9966-28-62-S6.xls]
}

\section{Additional File 7}

Gene Expression Changes in Unstable Genomic Regions for Gallbladder Cancer.

Click here for file

[http://www.biomedcentral.com/content/supplementary/1756-

9966-28-62-S7.xls]

\section{Additional File 8}

Over-representation Analysis - Tumor differentiation.

Click here for file

[http://www.biomedcentral.com/content/supplementary/1756-

9966-28-62-S8.xls]

\section{Additional File 9}

Over-representation Analysis - Vascular Invasion.

Click here for file

[http://www.biomedcentral.com/content/supplementary/1756-

9966-28-62-S9.xls]

\section{Additional File 10}

Over-representation Analysis - Perineural Invasion.

Click here for file

[http://www.biomedcentral.com/content/supplementary/1756-

9966-28-62-S10.xls]

\section{Acknowledgements}

This work was supported in part by the Christina and Paul Martin Foundation. The authors thank Tina Thomas for her help in preparing this manuscript for publication.

\section{References}

I. Miller G, Jarnagin WR: Gallbladder carcinoma. 2008, 34:306-3I2.

2. Randi G, Franceschi S, La VC: Gallbladder cancer worldwide: geographical distribution and risk factors. Int J Cancer 2006, i | 8(7): $159 \mid-602$.

3. Serra I, Calvo A, Baez S, Yamamoto M, Endoh K, Aranda W: Risk factors for gallbladder cancer. An international collaborative case-control study. Cancer 1996, 78(7): 1515-7.

4. Jarnagin WR, Fong Y, DeMatteo RP, Gonen M, Burke EC, Bodniewicz BJ, Youssef BAM, Klimstra D, Blumgart LH: Staging, resectability, and outcome in 225 patients with hilar cholangiocarcinoma. Ann Surg 200I, 234(4):507-I7.

5. Jarnagin WR, Ruo L, Little SA, Klimstra D, D'Angelica M, DeMatteo RP, Wagman R, Blumgart LH, Fong Y: Patterns of initial disease recurrence after resection of gallbladder carcinoma and hilar cholangiocarcinoma: implications for adjuvant therapeutic strategies. Cancer 2003, 98(8):1689-700.

6. Weber SM, Jarnagin WR, Klimstra D, DeMatteo RP, Fong Y, Blumgart LH: Intrahepatic cholangiocarcinoma: resectability, recurrence pattern, and outcomes. J Am Coll Surg 200I, 193(4):384-91.

7. Kuroki T, Tajima Y, Matsuo K, Kanematsu T: Genetic alterations in gallbladder carcinoma. Surg Today 2005, 35(2): 10I-5. 
8. Rashid A, Ueki T, Gao YT, Houlihan PS, Wallace C, Wang BS, Shen MC, Deng J, Hsing AW: K-ras mutation, p53 overexpression, and microsatellite instability in biliary tract cancers: a population-based study in China. Clin Cancer Res 2002, 8( I 0):3 I56-63.

9. Benckert C, Jonas S, Cramer T, Von MZ, Schafer G, Peters M, Wagner K, Radke C, Wiedenmann B, Neuhaus P, Höcker M, Rosewicz S: Transforming growth factor beta I stimulates vascular endothelial growth factor gene transcription in human cholangiocellular carcinoma cells. Cancer Res 2003, 63(5): $1083-92$.

10. Endo K, Yoon BI, Pairojkul C, Demetris AJ, Sirica AE: ERBB-2 overexpression and cyclooxygenase-2 up-regulation in human cholangiocarcinoma and risk conditions. Hepatology 2002, 36(2):439-50.

II. Isomoto H, Kobayashi S, Werneburg NW, Bronk SF, Guicciardi ME, Frank DA, Gores GJ: Interleukin 6 upregulates myeloid cell leukemia-I expression through a STAT3 pathway in cholangiocarcinoma cells. Hepatology 2005, 42(6):1329-38.

12. Kobayashi S, Werneburg NW, Bronk SF, Kaufmann SH, Gores G]: Interleukin-6 contributes to Mcl-I up-regulation and TRAIL resistance via an Akt-signaling pathway in cholangiocarcinoma cells. Gastroenterology 2005, I 28(7):2054-65.

13. Jarnagin WR, Klimstra DS, Hezel M, Gonen M, Fong Y, Roggin K, Cymes K, DeMatteo RP, D'Angelica M, Blumgart LH, Singh B: Differential cell cycle-regulatory protein expression in biliary tract adenocarcinoma: correlation with anatomic site, pathologic variables, and clinical outcome. J Clin Oncol 2006, 24(7): I I52-60.

14. Olshen AB, Venkatraman ES, Lucito R, Wigler M: Circular binary segmentation for the analysis of array-based DNA copy number data. Biostatistics 2004, 5(4):557-72.

15. Kang YK, Kim WH, Jang J]: Expression of G I-S modulators ( $\mathbf{p 5 3}$ pI6, p27, cyclin DI, Rb) and Smad4/Dpc4 in intrahepatic cholangiocarcinoma. Hum Pathol 2002, 33(9):877-83.

16. Kim YT, Kim J, Jang YH, Lee W], Ryu JK, Park YK, Kim SW, Kim WH, Yoon YB, Kim CY: Genetic alterations in gallbladder adenoma, dysplasia and carcinoma. Cancer Lett 200I, I69(1):59-68.

17. Chang HJ, Kim SW, Kim YT, Kim WH: Loss of heterozygosity in dysplasia and carcinoma of the gallbladder. Mod Pathol 1999, I 2(8):763-9.

18. Nakazawa K, Dobashi Y, Suzuki S, Fujii H, Takeda Y, Ooi A: Amplification and overexpression of c-erbB-2, epidermal growth factor receptor, and c-met in biliary tract cancers. J Pathol 2005, 206(3):356-65.

19. Roa JC, Roa I, Correa P, Vo Q, Araya JC, Villaseca M, Guzmán P, Schneider BG: Microsatellite instability in preneoplastic and neoplastic lesions of the gallbladder. J Gastroenterol 2005, 40(I):79-86.

20. Wang TL, Diaz LA Jr, Romans K, Bardelli A, Saha S, Galizia G, Choti M, Donehower R, Parmigiani G, Shih leM, lacobuzio-Donahue C, Kinzler KW, Vogelstein B, Lengauer C, Velculescu VE: Digital karyotyping identifies thymidylate synthase amplification as a mechanism of resistance to 5-fluorouracil in metastatic colorectal cancer patients. Proc Natl Acad Sci USA 2004, I 01 (9):3089-94.

21. Hoeller D, Hecker CM, Dikic I: Ubiquitin and ubiquitin-like proteins in cancer pathogenesis. Nat Rev Cancer 2006, 6( I 0):776-88.

22. Dikic I, Crosetto N, Calatroni S, Bernasconi P: Targeting ubiquitin in cancers. Eur J Cancer 2006, 42( I8):3095-102.

23. Vaclavicek A, Bermejo JL, Schmutzler RK, Sutter C, Wappenschmidt B, Meindl A, Kiechle M, Arnold N, Weber BH, Niederacher D, Burwinkel B, Bartram CR, Hemminki K, Försti A: Polymorphisms in the Janus kinase 2 (JAK)/signal transducer and activator of transcription (STAT) genes: putative association of the STAT gene region with familial breast cancer. Endocr Relat Cancer 2007, I 4(2):267-77.

24. Tam L, McGlynn LM, Traynor P, Mukherjee R, Bartlett JM, Edwards J: Expression levels of the JAK/STAT pathway in the transition from hormone-sensitive to hormone-refractory prostate cancer. Br J Cancer 2007, 97(3):378-83.

25. Dowlati $A$, Nethery D, Kern JA: Combined inhibition of epidermal growth factor receptor and JAK/STAT pathways results in greater growth inhibition in vitro than single agent therapy. Mol Cancer Ther 2004, 3(4):459-63.

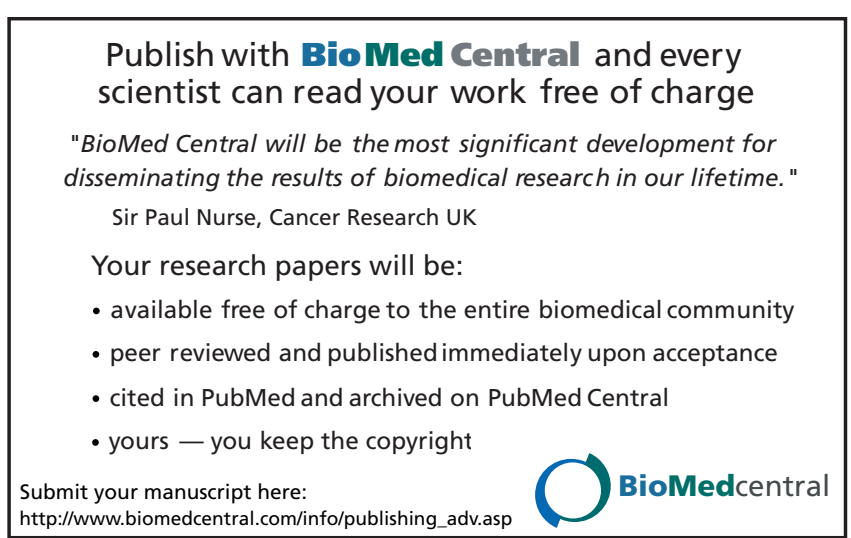

